\title{
Predictive value of ST segment elevation in cardiac pacing
}

\author{
A G ARNOLD
}

From the Department of Cardiology, fohn Radcliffe Hospital, Oxford

SUMMARY In 366 pacemaker patients the influence of intracardiac ST segment elevation on the fate (displacement or perforation) of permanent cardiac pacemaker electrodes was studied.

In one group of patients a retrospective analysis was carried out, the operator being aware of the degree of ST segment elevation and positioning the electrode to avoid very high or very low values wherever possible. In the second group a prospective trial was carried out. The final electrode position was determined solely by fluoroscopy and electrical threshold, and the ST segment shift measured afterwards.

The combined rates of electrode displacement and perforation did not differ between these groups. High levels of ST segment elevation, greater than $10 \mathrm{mV}$, were found to predispose to electrode perforation. On the other hand, low ST segments did not predict a displacement. It is concluded that the ideal positioning technique should seek a low electrical threshold, a stable position, and avoid high ST elevation.

The intracardiac electrocardiogram recorded via a pacemaker electrode varies according to the position of the electrode tip, and has been used to position temporary electrodes in the right ventricle when $x$-ray screening facilities are not available, ${ }^{1}$ or to aid correct positioning of the electrode for long-term pacing. ${ }^{2-4}$

In this study the spontaneous intracardiac electrocardiogram was analysed, not an evoked response. Both the QRS complex and the ST segment can be of assistance, and in this study we have concentrated on the latter (Fig.). ST segment elevation occurs when the electrode tip comes into contact with the ventricular endocardium, and is a result of the "current of injury". ${ }^{2}$ It varies from 0.6 to $15.0 \mathrm{mV}$ and falls with time. ${ }^{2}$ With impending perforation the ST segment elevation increases, and on perforation the ST segment becomes isoelectric, with $T$ wave inversion. ${ }^{5}$ It has been suggested that an optimal ST segment elevation of 2 to $8 \mathrm{mV}$ should be sought during insertion, since lower values might be followed by electrode displacement $^{6}$ and higher ones by electrode perforation, ${ }^{3} 78$ though few substantiating data have been published.

\section{Materials and methods}

The study was divided into two parts, the first Received for publication 31 March 1980
Fig. The spontaneous intracardiac electrocardiogram, showing the measurement of the ST segment elevation together with a one millivolt calibration wave. 
being a retrospective study of 163 pacemaker implantations (group 1). In these cases the final electrode position was partly determined by the intracardiac electrocardiogram. If the ST elevation was very high or very low the electrode position was moved in an attempt to achieve a more moderate value, though occasionally it could not be altered. The second part of the study was a prospective one of 203 consecutive insertions (group 2), where the intracardiac electrocardiogram was recorded only after final positioning, which it did not, therefore, influence.

All intracardiac electrocardiograms were recorded by an ultraviolet light recorder (frequency response $650 \mathrm{Hertz}$ ) and a permanent trace was kept, together with a $1 \mathrm{mV}$ calibration deflection. The study lasted from January 1977 to July 1979 with a minimum follow-up period of six months for each patient. The implantations were performed by several experienced operators. Several routes of insertion and several electrode types were used, but not modern helical or active fixation electrodes. One type of electrode produced very high failure rates, and the results of those insertions were excluded from the study.

Table 1 Outcome of pacing in groups 1 and 2

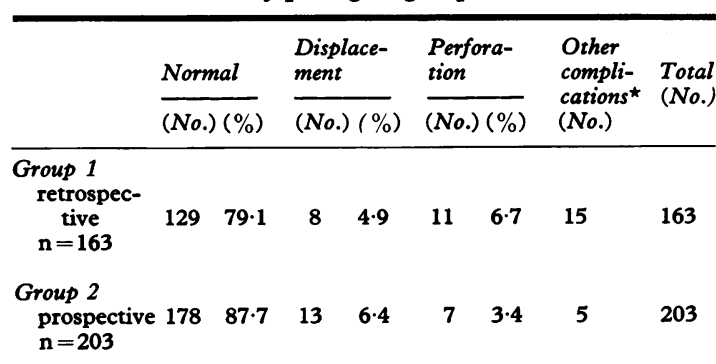

* Including fractured electrodes, elevated thresholds, and pacemaker cavity infections.

The electrocardiograms were analysed for the height of the ST elevation, and for the shape of the $T$ wave. The ST elevation found was allocated into three subgroups, 0 to $4.9 \mathrm{mV}, 5$ to $9.9 \mathrm{mV}$, and greater than $10 \mathrm{mV}$. These, and the shape of the $T$ wave, were then compared with the outcome of the pacemaker implantation, and the results tested for statistical significance by the $\chi^{2}$ test.

\section{Results}

The overall rates of displacement and perforation in groups 1 and 2 are shown in Table 1. ST elevation tended to be lower in group 2 (group 1 , mean $7 \cdot 33$, $\mathrm{SD}+3 \cdot 5 ;$ group 2 , mean $5 \cdot 76, \mathrm{SD} \pm 3 \cdot 81, \mathrm{p}<0.001$ ).
Table 2 Effect on outcome on ST elevation

\begin{tabular}{|c|c|c|c|c|c|c|c|}
\hline & \multirow[b]{3}{*}{ Group } & \multicolumn{6}{|c|}{$S T$ elevation } \\
\hline & & \multicolumn{2}{|c|}{0 to 4.9} & \multicolumn{2}{|c|}{5 to 9.9} & \multicolumn{2}{|l|}{$10 \rightarrow$} \\
\hline & & $\begin{array}{l}(N) \\
n=\end{array}$ & ${ }_{1}^{(\%)}$ & $\begin{array}{l}(N) \\
n=\end{array}$ & ${ }_{86}^{(\%)}$ & $\begin{array}{l}(N o .) \\
n=59\end{array}$ & $(\%)$ \\
\hline Normal & $\begin{array}{l}1 \\
2 \\
\text { Total }\end{array}$ & $\begin{array}{r}22 \\
85 \\
107\end{array}$ & $88 \cdot 4$ & $\begin{array}{r}84 \\
69 \\
153\end{array}$ & $82 \cdot 3$ & $\begin{array}{l}23 \\
24 \\
47\end{array}$ & $79 \cdot c$ \\
\hline Displacement & $\begin{array}{l}1 \\
2 \\
\text { Total }\end{array}$ & $\begin{array}{l}1 \\
6 \\
7\end{array}$ & $5 \cdot 8$ & $\begin{array}{r}6 \\
5 \\
11\end{array}$ & 5.9 & $\begin{array}{l}1 \\
2 \\
3\end{array}$ & $5 \cdot 1$ \\
\hline Perforation & $\begin{array}{l}1 \\
2 \\
\text { Total }\end{array}$ & $\begin{array}{l}0 \\
1 \\
1\end{array}$ & 0.8 & $\begin{array}{l}6 \\
2 \\
8\end{array}$ & $4 \cdot 3$ & $\begin{array}{l}5 \\
4 \\
9\end{array}$ & $15 \cdot 2$ \\
\hline Other* & $\begin{array}{l}1 \\
2 \\
\text { Total }\end{array}$ & $\begin{array}{l}3 \\
3 \\
6\end{array}$ & 5 & $\begin{array}{r}12 \\
2 \\
14\end{array}$ & 7.5 & $\begin{array}{l}0 \\
0 \\
0\end{array}$ & 0 \\
\hline
\end{tabular}

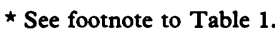

Though there was a lower rate of perforation and a higher rate of displacement in group 2 compared with group 1 , these differences were not significant. The combined rates of perforation and displacement were similar in the two groups. Other complications, such as electrode fracture, were commoner in group 1 , where the follow-up period was slightly longer (group 1, mean 23.1 months; group 2, mean 18.4 months).

The outcome of pacemaker implantation is related to the height of ST elevation in Table 2. The relation of ST elevation to displacement was not significant, but there was a strong positive correlation between raised $S T$ elevation and perforation $(\mathrm{p}<0.001)$.

In Tables 3 and 4 the presence of $T$ wave inversion was matched with the degree of ST elevation, and with the outcome of pacing, and it was clear that there was no strong association. Both high and low ST elevation were more often associated with $T$ wave inversion.

When we analysed our data in different groupings ( 0 to $2 \mathrm{mV}, 2$ to $8 \mathrm{mV}, 8 \mathrm{mV}$ upwards) our findings were unaltered.

Table 3 Relation of $T$ wave to $S T$ elevation in prospective study

\begin{tabular}{|c|c|c|c|c|c|c|}
\hline \multirow{2}{*}{$\begin{array}{l}\text { ST elevation } \\
(m V)\end{array}$} & \multicolumn{2}{|c|}{ Upright $T$} & \multicolumn{2}{|c|}{ Inverted $T$} & \multicolumn{2}{|c|}{ Isoelectric $T$} \\
\hline & $(N o)$. & $(\%)$ & (No.) & $(\%)$ & (No.) & $(\%)$ \\
\hline $\begin{array}{l}0-4.9 \\
n=95\end{array}$ & 34 & $35 \cdot 7$ & 40 & $42 \cdot 1$ & 21 & $22 \cdot 1$ \\
\hline $\begin{array}{l}5-9 \cdot 9 \\
n=78\end{array}$ & 34 & 43.6 & 14 & $17 \cdot 9$ & 30 & $38 \cdot 5$ \\
\hline $\begin{array}{l}10 \text { Plus } \\
\mathrm{n}=30\end{array}$ & 7 & $23 \cdot 3$ & 9 & 30 & 14 & $46 \cdot 7$ \\
\hline
\end{tabular}




\section{Discussion}

Despite advances in pacemaker implantation techniques, the rate of displacement remains at around 10 per cent, ${ }^{9}$ and electrode perforation is also a significant problem. ${ }^{1011}$ It is therefore important to minimise these risks by seeking an optimal position of the electrode in the right ventricle. Though some centres measure ST elevation during pacemaker implantation, others do not, and its value has not been fully studied previously.

In group 2 electrode positioning was undertaken in ignorance of the degree of ST elevation, which tended to be lower than in group 1. The overall rate of pacemaker complications (perforation plus displacement) was no higher in this group, despite the fact that the intracardiac electrocardiogram had not been used during positioning.

Table 4 Relation of $T$ wave to pacemaker outcome in the prospective study

\begin{tabular}{|c|c|c|c|c|c|c|}
\hline \multirow{2}{*}{$\begin{array}{l}\text { Pacemaker } \\
\text { outcome }\end{array}$} & \multicolumn{2}{|c|}{ Upright $T$} & \multicolumn{2}{|c|}{ Inverted $T$} & \multicolumn{2}{|c|}{ Isoelectric $T$} \\
\hline & (No.) & $(\%)$ & (No.) & $(\%)$ & (No.) & $(\%)$ \\
\hline $\begin{array}{l}\text { Normal* } \\
n=183\end{array}$ & 67 & $36 \cdot 6$ & 58 & $31 \cdot 7$ & 58 & $31 \cdot 7$ \\
\hline $\begin{array}{l}\text { Displacement } \\
n=13\end{array}$ & 6 & $46 \cdot 2$ & 3 & $23 \cdot 1$ & 4 & $30 \cdot 8$ \\
\hline $\begin{array}{l}\text { Perforation } \\
n=7\end{array}$ & 2 & 28.6 & 2 & $28 \cdot 6$ & 3 & $42 \cdot 9$ \\
\hline
\end{tabular}

* Including five patients with other complications (Table 1).

Higher levels of ST elevation were clearly associated with an increased liability to perforation, but low levels were not associated with an increased liability to displacement as a recent study ${ }^{6}$ claimed. These workers described ST elevation of less than $2 \mathrm{mV}$ as unsatisfactory, but the range of ST elevation in their patients with displacement was similar to the range in their normal controls, with no statistical difference being shown.

Intracardiac electrocardiograms should be routinely monitored during implantation of permanent cardiac pacemaker electrodes, since the height of ST elevation is of some predictive value; levels between 0 and $10 \mathrm{mV}$ are acceptable. $T$ wave inversion is of no significance.

I would like to thank Professor P Sleight and Dr D Bennett for their assistance with this study.

\section{References}

1 Chatterjee K, Sutton R, Layton CA, Edwards A. The cavity electrocardiogram in emergency artificial pacing. Postgrad Med f 1969; 45: 713-7.

2 Furman S, Hurzeler P, deCaprio V. The ventricular endocardial electrogram and pacemaker sensing. f Thorac Cardiovasc Surg 1977; 73: 258-66.

3 Harris AM. Transvenous pacing. Br $\mathcal{f}$ Hosp Med 1969; 1: 1131-5.

4 Gulotta SJ. Transvenous cardiac pacing. Technics for optimal electrode positioning and prevention of coronary sinus placement. Circulation 1970; 42: 701-18.

5 Vera Z, Janzen DA, Awan NA, Mason DT. Perforation of heart by pacemaker electrodes: an experimental study (abstract). Clin Res 1976; 24: 244A.

6 Parsonnet V, Bilitch M, Furman S, et al. Early malfunction of transvenous pacemaker electrodes. A three-center study. Circulation 1979; 60: 590-6.

7 Sutton R, Norman J. The cardiac electrogram in demand pacing. In: J Norman, A Rickards, eds. Proceedings of the pacemaker colloquium. Dieren: Vitatron Medical, 1976: 178-81.

8 Gialafos J, Kolettis M, Hadjigeorge C, Georgiou V, Avgoustakis D. The significance of intraventricular electrocardiogram in artificial heart pacing. Acta Cardiol (Brux) 1975; 30: 487-97.

9 Brewster GM, Evans AL. Displacement of pacemaker leads-a 10 year survey. $B r$ Heart $\mathcal{f}$ 1979; 42: 266-70.

10 Dancy M, Jackson G, Lau OJ, Farnsworth A. Successful treatment of myocardial perforation and tamponade after temporary endocardial pacing. $\mathrm{Br}$ Med f 1978; i: 79-80.

11 Rubenfire M, Anbe DT, Drake EH, Ormond RS. Clinical evaluation of myocardial perforation as a complication of permanent transvenous pacemakers. Chest 1973; 63: 185-8.

Requests for reprints to Dr A G Arnold, Department of Cardiology, John Radcliffe Hospital, Oxford OX3 9DU. 